\title{
BMJ
}

\section{Perceptions of genetic discrimination among people at risk for Huntington's disease: a cross sectional survey}

\author{
Yvonne Bombard, postdoctoral fellow, ${ }^{1,5}$ Gerry Veenstra, associate professor, ${ }^{2}$ Jan M Friedman, professor, \\ Susan Creighton, genetic counsellor and clinical assistant professor, ${ }^{1}$ Lauren Currie, research assistant, \\ Jane S Paulsen, professor, ${ }^{3}$ Joan L Bottorff, professor and director, ${ }^{4}$ Michael R Hayden, Canada Research chair \\ in Human Genetics and Molecular Medicine, University Killam professor ${ }^{1}$ the Canadian Respond-HD \\ Collaborative Research Group
}

Department of Medical Genetics, University of British Columbia, Vancouver, BC, V5Z 4H4, Canada (institution where the research was conducted)

${ }^{2}$ Department of Sociology, University of British Columbia, Vancouver, BC, V6T 1Z1, Canada

${ }^{3}$ Departments of Psychiatry, Neurology, Psychology and Neurosciences, University of lowa, lowa City, lowa, 52242, USA

${ }^{4}$ Faculty of Health and Social Development, Institute of Healthy Living and Chronic Disease

Prevention, University of British Columbia Okanagan, Kelowna, BC, V1V 1V7, Canada

${ }^{5}$ Department of Health Policy, Management and Evaluation, University of Toronto, Toronto, Ontario, M5T 3M6, Canada

Correspondence to: M R Hayden mrh@cmmt.ubc.ca

Cite this as: BMJ 2009;338:b2175 doi:10.1136/bmi.b2175 perceived unfair treatment of individuals or their

\section{ABSTRACT}

Objective To assess the nature and prevalence of genetic discrimination experienced by people at risk for Huntington's disease who had undergone genetic testing or remained untested.

Design Cross sectional, self reported survey.

Setting Seven genetics and movement disorders clinics servicing rural and urban communities in Canada.

Participants 233 genetically tested and untested asymptomatic people at risk for Huntington's disease (response rate 80\%): 167 underwent testing (83 had the Huntington's disease mutation, $84 \mathrm{did}$ not) and 66 chose not to be tested.

Main outcome measures Self reported experiences of genetic discrimination and related psychological distress based on family history or genetic test results.

Results Discrimination was reported by 93 respondents (39.9\%). Reported experiences occurred most often in insurance (29.2\%), family (15.5\%), and social (12.4\%) settings. There were few reports of discrimination in employment $(6.9 \%)$, health care $(8.6 \%)$, or public sector settings (3.9\%). Although respondents who were aware that they carried the Huntington's disease mutation reported the highest levels of discrimination, participation in genetic testing was not associated with increased levels of genetic discrimination. Family history of Huntington's disease, rather than the result of genetic testing, was the main reason given for experiences of genetic discrimination. Psychological distress was associated with genetic discrimination ( $\mathrm{P}<0.001)$.

Conclusions Genetic discrimination was commonly reported by people at risk for Huntington's disease and was a source of psychological distress. Family history, and not genetic testing, was the major reason for genetic discrimination.

\section{INTRODUCTION}

Genetic medicine offers many diagnostic, treatment, and reproductive options that can inform decision making and relieve uncertainty. However, the powerful new technologies of genomics have also produced fear of misuse of genetic information including discrimination. ${ }^{1-4}$ Genetic discrimination refers to the family members based on presumed or actual genetic differences as opposed to physical features..$^{5}$ Fear of genetic discrimination has prevented individuals from undergoing genetic testing ${ }^{36}$ and participating in genetic research. ${ }^{7}$ This widespread concern about genetic discrimination has heralded federal legislative developments in the United States-namely, the Genetic Information Nondiscrimination Act, which prohibits the use of genetic information in health insurance and employment related assessments. ${ }^{8}$ This act was signed into law on 21 May 2008 after near unanimous support from the House of Representatives and the Senate.

Despite these significant legislative efforts to protect individuals from the potential of genetic discrimination, the frequency and context of genetic discrimination remains largely undocumented. Reports of genetic discrimination have been anecdotal, and allegations of discrimination have usually been based on presence of disease in contrast to genetic predisposition. $^{25910}$ Despite calls for empirical research to address the lack of evidence for genetic discrimination, ${ }^{11}$ no large scale empirical study has investigated the nature and prevalence of genetic discrimination in a tested and untested genetic population that is currently healthy but is predicted by genetic testing to develop a genetic disease.

Huntington's disease was the first autosomal dominant genetic disease for which a predictive test was developed that allows people at risk to know with certainty whether they have inherited the causative mutation before they become symptomatic. ${ }^{12} 13$ Huntington's disease is an inherited neurodegenerative psychiatric disorder that usually manifests in midlife as a triad of psychiatric, cognitive, and movement disturbances. Individuals affected with Huntington's disease experience mood and personality changes, progressive cognitive decline, and worsening movement disorder which end in death about 15 -20 years from diagnosis. ${ }^{14}$ No treatment is available to alter 
Questions asked about genetic discrimination in the survey

\section{Discrimination based on family history}

We are interested in learning about experiences with discrimination, by this we mean being unfairly prevented from doing something, or being treated unfairly. Have you ever experienced discrimination in any of the following situations* because of your family history of Huntington's disease?

Discrimination based on genetic test results We are interested in learning about experiences with discrimination, by this we mean being unfairly prevented from doing something, or being treated unfairly. Have you ever experienced discrimination in any of the following situations* because of your genetic test results?

*See table 2 for the list of situations offered.

the course of the disease. Before the introduction of predictive testing, concerns were raised about whether it was ethical to offer testing without the availability of a treatment and whether such testing would lead to discriminatory practices against healthy people who were found to carry the mutation..$^{1516}$

It has been over 20 years since the inception of genetic testing for Huntington's disease, yet little is known about whether predictive testing results in discrimination. While discrimination on the basis of family history has been documented, ${ }^{17}$ the question of whether predictive testing confers a heightened risk of discrimination has yet to be answered for any disease. This study examined the nature and prevalence of genetic discrimination among asymptomatic individuals at risk for Huntington's disease. We hypothesised that those who had been tested would be at greater risk for genetic discrimination.

\section{PARTICIPANTS AND METHODS}

\section{Study population}

We undertook a cross sectional, self reported survey of asymptomatic people at risk for Huntington's disease in 2006. Seven genetics and movement disorders clinics servicing rural and urban communities in 10 Canadian provinces participated in the study. Approval of the relevant research ethics boards was received, and written informed consent was received from each participant.

We targeted asymptomatic individuals at risk for Huntington's disease. We classified each person in the study according to whether they had been genetically tested for Huntington's disease and, if so, whether they had tested positive: from these answers we produced three categories - not tested, tested negative for disease, and tested positive for disease. We considered only experiences of discrimination based on genetic information and excluded those that occurred after symptoms of Huntington's disease had developed. The population of interest included all individuals age $\geq 18$ years from families with Huntington's disease who had a Unified Huntington's Disease
Rating Scale (UHDRS) ${ }^{18}$ score of $\leq 2$ and had not been found to have signs or symptoms of Huntington's disease within the past year.

Development of the survey instrument and testing

Development of our survey instrument was informed by a previous qualitative study of genetic discrimination among people at risk for Huntington's disease, ${ }^{1920}$ and it included questions adapted (with permission) from validated instruments. ${ }^{2122}$ An expert reference group from the Huntington's Disease Medical Clinic at the University of British Columbia validated the questionnaire used for our study. Cognitive interviews were used to test for uniformity in comprehension and comfort with response formats, instructions, and skip patterns. The final questionnaire was mailed to 19 individuals at risk for Huntington's disease to pilot data collection procedures (see appendix 1 on bmj.com).

The final questionnaire included 122 questions. The sections focused on (1) genetic status and family history of Huntington's disease, (2) perceptions of genetic testing, (3) concerns and experiences of knowing about family history, (4) concerns and experiences of knowing genetic test results, (5) specific incidents of unfair treatment, (6) thoughts and experiences related to insurance, (7) knowledge and attitudes towards genetic issues, and (8) socio-demographic information. We report on results pertaining to sections (3) and (4) related to experiences of genetic discrimination based on family history and genetic test results.

\section{Assessment of family history}

The family history of respondents was assessed using the following questions:

- In approximately what year did you first become aware that Huntington's disease was in your family?

- Which of the following best describes your experience with Huntington's disease? (a) I have had no prior experience with people who had Huntington's disease; (b) I have known people who have had early symptoms of Huntington's disease; (c) I have known people who have had severe disease or have died.

\section{Assessment of genetic status}

The genetic status of the respondents was assessed using the following questions:

- Have you had a genetic test for Huntington's disease?

- Did you get a positive test result (that is, have you inherited the Huntington's disease gene expansion?)

Responses to these questions formed the basis for classifying individuals as mutation positive, mutation negative, or not tested.

\section{Assessment of experiences of genetic discrimination}

We asked respondents whether they had ever experienced discrimination in various situations because of 
their family history or based on their genetic test results (see box). We defined discrimination as "being unfairly prevented from doing something or being treated unfairly," which was the dominant interpretation provided by participants in the initial qualitative study ${ }^{1920}$ and is consistent with the well established and validated definitions of discrimination ${ }^{2123-25}$ and of genetic discrimination specifically. ${ }^{2022}$

The respondents were provided with a total of 23 possible contexts for discrimination (as listed in table 2). Possible responses were "yes," "no," and "not applicable." Respondents who answered "yes" to any item were considered to have experienced genetic discrimination and were counted once. In order to identify the prevalence of genetic discrimination in major settings, we collapsed the 23 items into six settings - insurance, employment, social, family, public sector, and health care (see table 2). Settings were not mutually exclusive, with respondents selecting all that applied.

\section{Assessment of psychological distress}

Psychological distress was chosen a priori to be a primary outcome measure because it has been associated with racial, sexual, and ethnic discrimination. ${ }^{26}$ Respondents who reported one or more experience $(\mathrm{s})$ of

Table 1|Demographic characteristics of 233 asymptomatic respondents at risk for Huntington's disease. Values are numbers (percentages) unless stated otherwise

\begin{tabular}{|c|c|c|c|c|c|}
\hline & \multirow[b]{2}{*}{ Total $(n=233)$} & \multicolumn{2}{|c|}{ Genetic test for mutation } & \multirow[b]{2}{*}{ Not tested $(n=66)$} & \multirow{2}{*}{$\begin{array}{l}\text { P value of } \\
\text { difference }\end{array}$} \\
\hline & & Positive $(n=83)$ & Negative $(n=84)$ & & \\
\hline Women & $153(65.7)$ & $53(63.9)$ & $52(61.9)$ & $48(72.7)$ & \multirow{2}{*}{0.35} \\
\hline Men & $80(34.3)$ & $30(36.1)$ & $32(38.1)$ & $18(27.3)$ & \\
\hline Mean (SD) age (years) & $45.5(11.7)$ & $47.0(11.0)$ & $46.0(13.7)$ & $42.9(9.5)$ & 0.09 \\
\hline \multicolumn{6}{|l|}{ Marital status (n=231): } \\
\hline Married or partnership & $176(76.2)$ & $64(79.0)$ & $59(70.2)$ & $53(80.3)$ & \multirow{2}{*}{0.27} \\
\hline Single, separated, divorced, widowed & $55(23.8)$ & $17(21.0)$ & $25(29.8)$ & $13(19.7)$ & \\
\hline \multicolumn{6}{|l|}{ Education ( $n=226)$ : } \\
\hline Some college and higher & $206(91.2)$ & $77(95.1)$ & $72(88.9)$ & $57(89.1)$ & \multirow{2}{*}{0.30} \\
\hline High school or lower & $20(8.8)$ & $4(4.9)$ & $9(11.1)$ & $7(10.8)$ & \\
\hline \multicolumn{6}{|l|}{ Employment $(n=228):$} \\
\hline Employed & $165(72.4)$ & $56(68.3)$ & $55(67.1)$ & $54(84.4)$ & \multirow{3}{*}{$-\dagger$} \\
\hline Unemployed and seeking work & $11(4.8)$ & $4(4.9)$ & $3(3.7)$ & $4(6.3)$ & \\
\hline Unemployed and not seeking work & $52(22.8)$ & $22(26.8)$ & $24(29.3)$ & $6(9.4)$ & \\
\hline \multicolumn{6}{|l|}{ No of children (n=232): } \\
\hline$\geq 1$ & $169(72.8)$ & $61(74.4)$ & $64(76.2)$ & $44(66.7)$ & \multirow[t]{2}{*}{0.40} \\
\hline None & $63(27.2)$ & $21(25.6)$ & $20(23.8)$ & $22(33.3)$ & \\
\hline \multicolumn{6}{|l|}{ Community or setting $(n=233) \ddagger:$} \\
\hline Urban & $192(82.8)$ & $65(78.3)$ & $73(86.9)$ & $54(81.8)$ & \multirow{2}{*}{0.34} \\
\hline Rural & $41(17.7)$ & $18(21.7)$ & $11(13.1)$ & $12(18.2)$ & \\
\hline \multicolumn{6}{|l|}{$\begin{array}{l}\text { Time since genetic testing (years) } \\
(n=150) \text { : }\end{array}$} \\
\hline$\leq 4$ & $77(51.3)$ & $37(50.0)$ & $40(52.6)$ & $\mathrm{N} / \mathrm{A}$ & \multirow{3}{*}{0.80} \\
\hline 5-9 & $35(23.3)$ & $19(25.7)$ & $16(21.1)$ & $\mathrm{N} / \mathrm{A}$ & \\
\hline$\geq 10$ & $38(25.3)$ & $18(24.3)$ & $20(26.3)$ & $\mathrm{N} / \mathrm{A}$ & \\
\hline \multicolumn{6}{|l|}{$\begin{array}{l}\text { Experience with people with } \\
\text { Huntington's disease }(n=226) \text { : }\end{array}$} \\
\hline No prior experience & $44(19.5)$ & $15(18.5)$ & $16(19.8)$ & $13(16.0)$ & \multirow{3}{*}{0.057} \\
\hline Known people with early symptoms & $25(11.1)$ & $15(18.5)$ & $3(3.7)$ & $7(8.6)$ & \\
\hline $\begin{array}{l}\text { Known people with severe disease or } \\
\text { who have died }\end{array}$ & $157(69.5)$ & $51(63.0)$ & $62(76.5)$ & $44(54.3)$ & \\
\hline \multicolumn{6}{|l|}{$\begin{array}{l}\text { Time since learning of family history of } \\
\text { Huntington's disease (years) }(n=211) \text { : }\end{array}$} \\
\hline$\leq 9$ & $61(28.9)$ & $23(29.9)$ & $18(24.3)$ & $20(33.3)$ & \multirow{5}{*}{0.38} \\
\hline $10-19$ & $56(26.5)$ & $25(32.5)$ & $15(20.3)$ & $16(26.7)$ & \\
\hline $20-29$ & $48(22.7)$ & $15(19.5)$ & $19(25.7)$ & $14(23.3)$ & \\
\hline $30-39$ & 33 (15.6) & 11 (14.3) & 14 (18.9) & $8(13.3)$ & \\
\hline$\geq 40$ & $13(6.2)$ & $3(3.9)$ & $8(10.8)$ & $2(3.3)$ & \\
\hline
\end{tabular}

*Missing values are excluded, values are two-sided. Analysis by $2 \times 3$ Pearson's $x^{2}$ test for categorical variables, and one-way analysis of variance for continuous variables.

tDoes not meet assumptions of $x^{2}$ test.

$\ddagger$ Based on Statistics Canada’s rural postal code definition (Statistics Canada. Rural and small town Canada analysis bulletin. 2001 November 3(3)). 
genetic discrimination were asked to rank the resulting level of distress they experienced, in general, on a scale of 1-5, with 5 being the most distressing.

\section{Demographic information}

Respondents were asked to report their age, sex, marital status, employment status, whether they had children, highest level of education attained, cultural background, income level, type(s) of insurance purchased, and which parent had Huntington's disease and the age of disease onset.

\section{Administration of the survey}

The questionnaires were administered during individuals' annual scheduled clinic appointments or by mail between June and December 2006. Using the Dillman tailored design survey method, ${ }^{27}$ we mailed postal respondents the questionnaire, an introductory letter, a postage-paid return envelope, and a $\$ 25$ honorarium

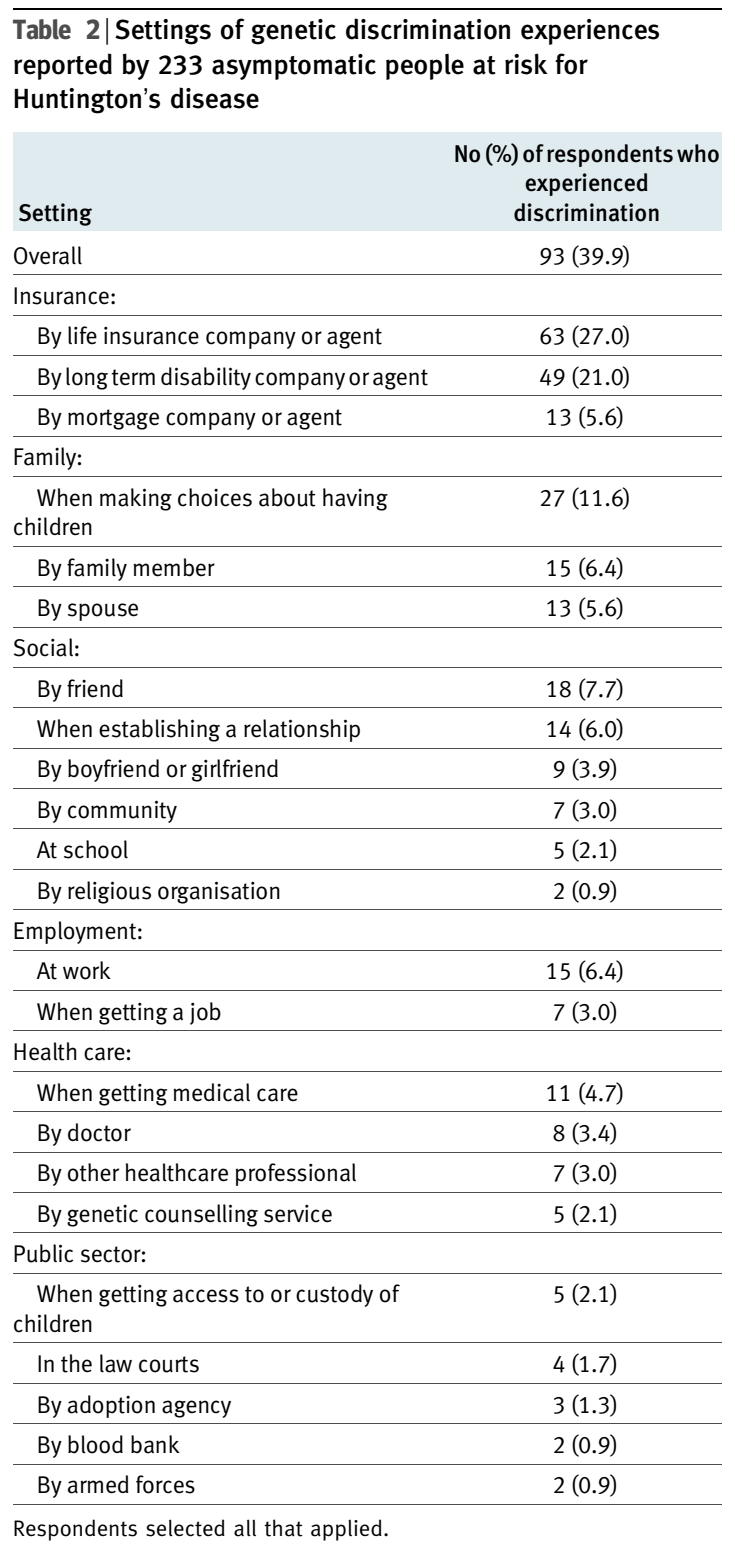

by health professionals at each clinic. Written consent was obtained from all respondents.

\section{Statistical analysis}

Descriptive statistics were calculated for the experiences and prevalence of genetic discrimination. We used Fisher's exact test and Pearson's $\chi^{2}$ tests of significance to investigate baseline demographic differences between the study groups (tested positive, tested negative, and not tested) and differences between the groups reporting experiences of genetic discrimination in the six settings. Significance tests were two tailed, and $\alpha$ was set at 0.05 . The false discovery rate procedure ${ }^{28}$ was used for multiple comparisons in our exploratory analyses (differences in genetic discrimination between groups within the various settings, representing 30 comparisons). Since fewer comparisons were being made in our hypothesis-driven analyses (differences in genetic discrimination between all tested, tested positive, tested negative, and untested respondents - that is, four comparisons), correction for multiple comparisons was unnecessary.

\section{RESULTS}

Characteristics of the respondents

Of 299 people invited to participate, 239 returned a completed questionnaire, representing a response rate of $80 \%$. Six surveys were excluded because the individuals had UHDRS disease scores $>2$ at some point after consenting to join the study but before completing the survey questionnaire, rendering an adjusted response rate of $79.5 \%$ (233/293). Table 1 shows the characteristics of the remaining 233 asymptomatic respondents. No significant differences in baseline characteristics were detected between the study groups. The sociodemographic characteristics of our sample are similar to those of other Huntington's disease populations who attend Huntington's disease clinics ${ }^{29-32}$ except that our sample was somewhat older and better educated. Additionally, responders and non-responders did not significantly differ with respect to sex $(\mathrm{P}=0.206)$, average age $(\mathrm{P}=0.077)$, genetic test status $(\mathrm{P}=0.334)$, and mutation status $(\mathrm{P}=0.365)$ (details in supplemental table $\mathrm{A}$ on bmj.com).

\section{Nature and extent of genetic discrimination}

Genetic discrimination was reported by 93 respondents (39.9\%). Discrimination experiences were most prevalent in insurance $(29.2 \%)$, family $(15.5 \%)$, and social $(12.4 \%)$ settings, with discrimination in employment, healthcare, and public sector settings reported much less often (table 2).

There were no significant differences in reported experiences of genetic discrimination in the insurance, healthcare, and public sector settings among respondents who had been genetically tested compared with those not, nor by those who tested positive compared with those who tested negative (table 3). Although not at levels considered significant after adjusting for multiple comparisons, respondents who had been 
genetically tested for Huntington's disease, particularly those who tested positive, tended to report higher levels of genetic discrimination in interpersonal domains such as family, social, and employment settings rather than institutional related settings.

\section{Genetic testing and genetic discrimination}

Overall, tested and untested respondents reported similar levels of discrimination $(71(42.5 \%) \quad v 22$ (33.3\%), Fisher's exact test $\mathrm{P}=0.236)$. However, when comparing discrimination experiences between those who tested positive for the mutation, those who tested negative, and those who remained untested, the tested positive respondents reported the highest levels of discrimination (42 (50.6\%) tested positive $v 29(34.5 \%)$ tested negative $v 22(33.3 \%)$ untested, $\chi^{2}$ test $\mathrm{P}=0.046$; and tested positive $v$ tested negative, Fisher's exact test $\mathrm{P}=0.042$ ). Interestingly, the tested negative and untested respondents reported similar levels of discrimination experiences $(29(34.5 \%)$ v 22 (33.3\%), Fisher's exact test $\mathrm{P}=1.00$ ).

\section{Reported reasons for genetic discrimination}

Respondents' family history was reported as the main reason for genetic discrimination. Among the 71 tested respondents who reported genetic discrimination, 41 attributed their experiences to their family history, whereas only 13 believed that their genetic test results were the main reason for their discriminatory experiences. Seventeen tested respondents attributed their experiences to both family history and genetic test results.

\section{Psychological distress and genetic discrimination}

Psychological distress was significantly associated with the experience of genetic discrimination $-\mathrm{P} \leq 0.0001$ for discrimination based on family history, and $\mathrm{P}=0.011$ for discrimination based on genetic test results (because of the small sample sizes, ranks 1-3 and 4-5 were collapsed to represent low-moderate and high levels of distress respectively). Further, experiencing genetic discrimination in more situations was associated with increased levels of distress (Pearson's product-moment correlation coefficient $r=0.384$ based on family history and 0.526 based on genetic test results, both $\mathrm{P}<0.001)$.

\section{DISCUSSION}

This is the first study to report on the nature and prevalence of genetic discrimination among an asymptomatic tested and untested population and to distinguish between discrimination based on family history and genetic test results. Despite previous claims that genetic discrimination is rare ${ }^{3334}$ discrimination was reported by nearly $40 \%$ of the individuals we sampled. Genetic discrimination occurred most often in reference to life and disability insurance, and among family and friends (12.4-29.2\%). Surprisingly, there were few reports of genetic discrimination in employment, healthcare, or public sector settings (3.9-6.9\%). Interestingly, family history seems to be a major reason for experiences of genetic discrimination. Psychological distress was strongly associated with genetic discrimination $(\mathrm{P}<0.001)$.

Nearly one in three of the respondents reported insurance discrimination, largely by life and disability insurance companies in the forms of insurance rejection, premium increases, or requests to take a predictive test. Surprisingly, however, these experiences were not influenced by individuals' participation in genetic testing or their genetic test results; rather they were attributed to family history. Before the introduction of the Huntington's disease predictive testing programme, concerns were raised that insurance companies might misuse genetic testing by demanding "such a test before entering into a contract with someone at risk." 1516 Although such requests occurred, they were not limited to the tested group. Our results therefore do not support apprehensions that genetic testing

Table 3|Prevalence of genetic discrimination experiences reported by 233 asymptomatic people at risk for Huntington's disease by genetic testing and test result. Values are numbers (percentages) unless stated otherwise

\begin{tabular}{|c|c|c|c|c|c|c|c|c|}
\hline \multirow[b]{2}{*}{$\begin{array}{l}\text { Setting of } \\
\text { discrimination }\end{array}$} & \multirow[b]{2}{*}{$\begin{array}{c}\text { Total } \\
(n=233)\end{array}$} & \multicolumn{3}{|c|}{ Genetically tested } & \multirow[b]{2}{*}{$\begin{array}{l}\text { Not tested } \\
\quad(n=66)\end{array}$} & \multicolumn{3}{|c|}{$P$ value of difference } \\
\hline & & $\begin{array}{c}\text { Total } \\
(n=167)\end{array}$ & $\begin{array}{l}\text { Positive test } \\
\quad(n=83)\end{array}$ & $\begin{array}{c}\text { Negative } \\
\text { test }(n=84)\end{array}$ & & $\begin{array}{c}\text { Total tested } v \\
\text { not tested* }\end{array}$ & $\begin{array}{l}\text { Positive test } v \\
\text { negative test* }\end{array}$ & Overall† \\
\hline Overall & $93(39.9)$ & $71(42.5)$ & $42(50.6)$ & $29(34.5)$ & $22(33.3)$ & 0.236 & 0.042 & 0.046 \\
\hline Insurance & $68(29.2)$ & $53(31.7)$ & $31(37.3)$ & $22(26.2)$ & $15(22.7)$ & 0.202 & N/A & 0.112 \\
\hline Family & $36(15.5)$ & $31(18.6)$ & $19(22.9)$ & $12(14.3)$ & $5(7.6)$ & $0.044 \ddagger$ & 0.168 & $0.034 \S$ \\
\hline Social & $29(12.4)$ & $25(15.0)$ & $17(20.5)$ & $8(9.5)$ & $4(6.1)$ & 0.078 & 0.053 & $0.018 \pi$ \\
\hline Employment & $16(6.9)$ & $15(9.0)$ & $12(14.5)$ & $3(3.6)$ & $1(1.5)$ & -** & $0.003 \dagger \dagger$ & $0.003+\dagger$ \\
\hline Health care & $20(8.6)$ & $14(8.4)$ & $11(13.3)$ & $3(3.6)$ & $6(9.1)$ & 0.802 & $\mathrm{~N} / \mathrm{A}$ & 0.081 \\
\hline Public sector & $9(3.9)$ & $9(5.4)$ & $5(6.0)$ & $4(4.8)$ & $0(0.0)$ & -** & - $^{\star \star}$ & -** \\
\hline
\end{tabular}

*Fisher's exact test. Values are two sided.

†Positive test $v$ negative test $v$ not tested. Pearson's $x^{2}$ test. Values are two sided.

$\mathrm{N} / \mathrm{A}$ : post hoc comparison is not applicable as primary comparison was not significant (see corresponding overall $P$ value).

$\ddagger P$ value did not reach the required significance level adjusted for false discovery rate $(P \leq 0.014)$.

$\S$ Post hoc $P$ value (positive test $v$ not tested, $P=0.013$ ) was above the required significance level adjusted for false discovery rate $(P \leq 0.007)$

đPost hoc $\mathrm{P}$ value (positive test $v$ not tested, $\mathrm{P}=0.016)$ was above the required significance level adjusted for false discovery rate $(\mathrm{P} \leq 0.011)$.

$\star \star A s s u m p t i o n s$ of the $X^{2}$ test not met.

$\dagger+$ Post hoc $P$ values (positive test $v$ not tested, $P=0.007$; negative test $v$ not tested, $P=0.016$ ) were above the required significance levels adjusted for false discovery rate $(P \leq 0.005$ and $P \leq 0.010$, respectively). 
confers heightened levels of genetic discrimination related to insurance.

Surprisingly, family and social circles were the next major source of discriminatory experiences. One in five respondents reported genetic discrimination in these settings, mostly in reference to reproductive decision making and relationships. No survey to date has explored discrimination in areas other than institutional domains. Discrimination in the family must be viewed through a wider lens that captures the profound impact the presence of Huntington's disease and predictive testing can have on the family system. Often when Huntington's disease is present in a family, it becomes part of a family's identity and pattern of behaviour.

The advent of predictive testing for Huntington's disease introduced the opportunity to remove the uncertainty of a looming disease and to plan for the future, but with it comes the potential inability to cope with the predictive test results, both by the individual as well as by family members. This is particularly challenging given that no treatment exists to slow or prevent the disease. There was apprehension that disclosure of test results may precipitate depression, breakdown of family relationships, or suicide. ${ }^{1516}$ Likewise, the availability of genetic testing creates new pressures and dilemmas for the family. ${ }^{35}$ The decision to test itself can become a "litmus test by which relatives judge each other's loyalty to the family, ${ }^{, 35}$ and testing often produces disruption within the family. ${ }^{36}$ Clearly, the availability of predictive testing produces reactions towards those who test and those who choose not to test. This study provides further insight into the impact of genetic testing on the family and highlights a need to pay special attention to family and social domains during pretest and post-test counselling. These results also suggest the need for further research on genetic discrimination in this area.

Interestingly, tested respondents attributed their experiences of genetic discrimination to their family history more often than to their genetic test results. These results lend further support to the similar levels of discrimination seen between the tested and untested groups. Indeed, regardless of testing status, most individuals believed that family history was the predominant reason for their discriminatory experiences. Clearly, there is a need to shift the current focus of genetic discrimination as a genetic testing issue to one that equally highlights the role that family history plays in people's lives.

Psychological distress was strongly associated with genetic discrimination. Our results are consistent with previously documented associations of distress with racial, sexual, and ethnic discrimination. ${ }^{26}$ Still, the health outcomes of genetic discrimination have not been described, raising the effects of genetic discrimination to a mental health issue which requires appropriate counselling and support.

Discrimination in employment, healthcare, and public sector settings was infrequently cited by our respondents. Despite concern for genetic discrimination in employment, ${ }^{17}$ little discrimination seems to be occurring in this setting. The low levels of discrimination in the healthcare domain support the assumption that healthcare professionals have a better understanding of genetic risk and are likely to use such information appropriately. These findings may also be influenced by the existence in Canada of a healthcare system where access and treatment are universal and not determined by employment.

Our findings are particularly important in light of the recent US federal Genetic Information Nondiscrimination Act. This prohibits group and individual health insurers from using a person's and his or her family's genetic information in determining eligibility and setting premiums for health insurance and from requesting or requiring potential applicants to provide genetic test results. Furthermore, it bars employers from using genetic test results in their hiring, firing, job placement, or promotion decisions. ${ }^{8}$ Such legislative protection against genetic discrimination in health insurance would make a basic level of coverage accessible to all members of society without the need to disclose genetic information. However, by focusing exclusively on health insurance and employment, the legislation does not address the commonly occurring discrimination with regard to life and disability insurance, nor the genetic discrimination that occurs within social and family relationships. The areas of greatest need may not be protected by this legislation.

Legislation is not a feasible approach to regulate interactions within family and social relationships. Insight into the psychodynamics of genetic discrimination would be important in the development of appropriate intervention strategies to mitigate discrimination. Strategies might include comprehensive education and support programmes to inform and engage society about genetics to reduce ignorance and the resultant level of stigma and discrimination. Support groups are common for many hereditary disorders and could be used to strengthen social support networks and assist those who wish to lodge formal complaints against genetic discrimination. Ultimately, such structural interventions may be necessary to change the social climate around genetic disease.

\section{Limitations of study}

Our findings should be interpreted in light of our study's methodological limitations. Our findings are based on data from Canada, and may not be generalisable to jurisdictions without universal health care. The cross sectional design did not allow us to make conclusions about causal effects of genetic status or family history on experiences of genetic discrimination. Longitudinal studies with larger sample sizes are needed to draw definite causal conclusions and confirm the presence or absence of associations. In addition, discrimination experiences were self reported and could not be validated; thus, reported experiences are the respondents' perception of discrimination. It is thus possible that our results represent an overly optimistic view of the nature and extent of genetic 


\section{WHAT IS ALREADY KNOWN ON THIS TOPIC}

Genetic discrimination is a potential risk associated with genetic testing, and fear of it has prevented individuals from undergoing genetic testing and participating in genetic research

There is little evidence regarding the frequency and context of genetic discrimination after genetic testing

\section{WHAT THIS STUDY ADDS}

Genetic discrimination was a commonly reported experience and a source of distress for people at risk for Huntington's disease

Family history, and not genetic testing, was the major reason for genetic discrimination

discrimination. Alternatively, study participants may be more aware of the issue of genetic discrimination and thus be better able to recognise it (or its occurrence).

Our sampling strategy relied on reports of discrimination among people attending clinics and participating in research who may be more resourceful and better able to cope with the psychosocial consequences of testing or research. The motivation and emotional wellbeing of people who are connected with clinics and participate in research or predictive testing may therefore be unrepresentative of the general population at risk of Huntington's disease. Finally, our measure of psychological distress was not a diagnostic instrument. Psychological distress is a multidimensional concept that may not be fully captured by a single item.

\section{Implications of our results}

Our findings have implications beyond Huntington's disease. Indeed, the predictive testing programme for Huntington's disease, a classic monogenic disease, has served as a model for presymptomatic testing for several genetic and non-genetic diseases. ${ }^{37-39}$ Our findings also provide insights for genetic screening programmes for diseases associated with genes of small effect as well as other late onset and neurological conditions. Predictive testing for Huntington's disease represents an extreme model for an autosomal dominant disease of high penetrance for which there is a well validated test. Even in such an extreme case, our study highlights the importance of family history in people's experiences of genetic discrimination. Ultimately, asymptomatic individuals at genetic risk are at similar risk for discrimination because of their label of having a family history of disease.

We thank the families who made this study possible by sharing their experiences with us. We thank the members of the Hayden laboratory for insightful discussions and critical reading of this manuscript. Contributors: YB and MRH participated in the conception, development, analysis, and writing of this manuscript (and act as guarantors of the paper). YB led the overall implementation of the study, including data collection, recruitment and analysis. JMF participated in the development and interpretation of the study. SC and JSP participated in the design and recruitment of the study. GV and JLB participated in research design, questionnaire creation, data analysis, and writing of the manuscript. LC participated in the coordination of the project as well as data entry and management. YB and MRH had access to all the data in the study and take full responsibility for the integrity of the data and accuracy of the data analysis.
The contributors of the Canadian Respond-HD collaborative research group, who participated in the recruitment and administration of the survey, are : Mark Guttman and Christine Giambattista, Centre for Movement Disorders, Markham, Ontario; Mark Ludman, Jill Murphy, and Tina Babineau-Sturk, IWK Health Centre, Halifax, Nova Scotia; Patrick MacLeod and Jennifer Rice, Victoria General Hospital, Victoria, British Columbia; Wayne Martin and Marguerite Wieler, University of Alberta, Edmonton, Alberta; Wendy Meschino and Clare Gibbons, North York General Hospital, Toronto, Ontario; Lynn Raymond and Joji Decolongon, University of British Columbia, Vancouver, British Columbia; Oksana Suchowersky and Mary-Lou Klimek, University of Calgary, Calgary, Alberta.

Funding: Funding for this project from the Canadian Institutes of Health Research (CIHR) was received by MRH and JLB. Supplemental funding from the National Institutes of Health and the National Institute of Neurological Disorders and Stroke was awarded to JSP (No 3 R01 NS040068). YB was supported by the CIHR, the Michael Smith Foundation for Health Research, and the Child and Family Research Institute. None of these funding agencies played any role in the study design; in the collection, analysis, and interpretation of data; in the writing of the report; or in the decision to submit the article for publication. Competing interests: None declared.

1 Hall MA, McEwen JE, Barton JC, Walker AP, Howe EG, Reiss JA, et al. Concerns in a primary care population about genetic discrimination by insurers. Genet Med 2005;7:311-6.

2 Apse KA, Biesecker BB, Giardiello FM, Fuller BP, Bernhardt BA. Perceptions of genetic discrimination among at-risk relatives of colorectal cancer patients. Genet Med 2004;6:510-6.

3 Peterson EA, Milliron KJ, Lewis KE, Goold SD, Merajver SD. Health insurance and discrimination concerns and BRCA1/2 testing in a clinic population. Cancer Epidemiol Biomarkers Prev 2002;11:79-87.

4 Mayor S. Report warns of danger of genetic discrimination in the workplace. BMJ 2003;327:702

5 Billings PR, Kohn MA, de Cuevas M, Beckwith J, Alper JS, Natowicz MR. Discrimination as a consequence of genetic testing. Am J Hum Genet 1992;50:476-82.

6 Friedrich MJ. Preserving privacy, preventing discrimination becomes the province of genetics experts. JAMA 2002;288:815-6, 819.

7 Hadley DW, Jenkins J, Dimond E, Nakahara K, Grogan L, Liewehr DJ, et al. Genetic counseling and testing in families with hereditary nonpolyposis colorectal cancer. Arch Intern Med 2003;163:573-82.

8 Tanne JH. US Senate outlaws genetic discrimination. BMJ 2008;336:1038

9 Low L, King S, Wilkie T. Genetic discrimination in life insurance: empirical evidence from a cross sectional survey of genetic support groups in the United Kingdom. BMJ 1998;317:1632-5.

10 Lapham EV, Kozma C, Weiss JO. Genetic discrimination: perspectives of consumers. Science 1996;274:621-4.

11 Morrison PJ. Insurance, unfair discrimination, and genetic testing. Lancet 2005;366:877-80.

12 Quarrell OW, Meredith AL, Tyler A, Youngman S, Upadhyaya M, Harper PS. Exclusion testing for Huntington's disease in pregnancy with a closely linked DNA marker. Lancet 1987;i:1281-3.

13 Hayden MR, Hewitt J, Kastelein JJ, Langlois S, Wilson RD, Fox S, et al. First-trimester prenatal diagnosis for Huntington's disease with DNA probes. Lancet 1987; i:1284-5.

14 Hayden MR. Huntington's chorea. New York: Springer-Verlag, 1981.

15 Craufurd DI, Harris R. Ethics of predictive testing for Huntington's chorea: the need for more information. BMJ 1986;293:249-51.

16 Perry TL. Some ethical problems in Huntington's chorea. CMAJ 1981;125:1098-100.

17 Harper PS, Gevers S, de Wert G, Creighton S, Bombard Y, Hayden MR. Genetic testing and Huntington's disease: issues of employment Lancet Neurol 2004:3:249-52.

18 Siesling S, van Vugt JP, Zwinderman KA, Kieburtz K, Roos RA. Unified Huntington's disease rating scale: reliability and consistency. Huntington Study Group. Mov Disord 1998;13:915-9.

19 Bombard Y, Penziner E, Decolongon J, Klimek ML, Creighton S, Suchowersky O, et al. Managing genetic discrimination: strategies used by individuals found to have the Huntington disease mutation. Clin Genet 2007;71:220-31.

20 Bombard Y, Penziner E, Suchowersky O, Guttman M, Paulsen JS, Bottorff JL, et al. Engagement with genetic discrimination: concerns and experiences in the context of Huntington disease. Eur J Hum Genet 2008;16:279-89.

21 Krieger N, Smith K, Naishadham D, Hartman C, Barbeau EM. Experiences of discrimination: validity and reliability of a self-report measure for population health research on racism and health. Soc Sci Med 2005;61:1576-96 
22 Taylor S, Treloar S, Barlow-Stewart K, Stranger M, Otlowski M. Investigating genetic discrimination in Australia: a large-scale survey of clinical genetics clients. Clin Genet 2008;74:20-30.

23 Borrell LN, Jacobs DR Jr, Williams DR, Pletcher MJ, Houston TK, Kiefe $\mathrm{Cl}$. Self-reported racial discrimination and substance use in the coronary artery risk development in adults study. Am J Epidemiol 2007;166:1068-79.

24 Kessler RC, Mickelson KD, Williams DR. The prevalence, distribution, and mental health correlates of perceived discrimination in the United States. J Health Soc Behav 1999;40:208-30.

25 Krieger N, Sidney S, Coakley E. Racial discrimination and skin color in the CARDIA study: implications for public health research. Coronary artery risk development in young adults. Am J Public Health 1998;88:1308-13.

26 Krieger N. Embodying inequality: a review of concepts, measures, and methods for studying health consequences of discrimination. Int J Health Serv 1999;29:58.

27 Dillman D. Mail and internet surveys: the tailored design method. Toronto: John Wiley and Sons, 2000.

28 Curran-Everett D. Multiple comparisons: philosophies and illustrations. Am J Physiol Regul Integr Comp Physiol 2000;279:R1-8.

29 Babul R, Adam S, Kremer B, Dufrasne S, Wiggins S, Huggins M, et al. Attitudes toward direct predictive testing for the Huntington disease gene. Relevance for other adult-onset disorders. The Canadian Collaborative Group on Predictive Testing for Huntington Disease. JAMA 1993;270:2321-5.
30 Codori AM, Brandt J. Psychological costs and benefits of predictive testing for Huntington's disease. Am J Med Genet 1994;54:174-84.

31 Quaid KA, Morris M. Reluctance to undergo predictive testing: the case of Huntington disease. Am J Med Genet 1993;45:41-5.

32 Wiggins S, Whyte $P$, Huggins $M$, Adam S, Theilmann J, Bloch M, et al. The psychological consequences of predictive testing for Huntington's disease. Canadian collaborative study of predictive testing. N Engl J Med 1992;327:1401-5.

33 Greely HT. Banning genetic discrimination. N Engl J Med 2005;353:865-7.

34 Walker FO. Huntington's disease. Lancet 2007;369:218-28.

35 Sobel SK, Cowan DB. Impact of genetic testing for Huntington disease on the family system. Am J Med Genet 2000;90:49-59.

36 Kessler S. Predictive testing for Huntington disease: a psychologist's view. Am J Med Genet 1994;54:161-6.

37 Evers-Kiebooms G, Welkenhuysen M, Claes E, Decruyenaere M, Denayer $\mathrm{L}$. The psychological complexity of predictive testing for late onset neurogenetic diseases and hereditary cancers: implications fo multidisciplinary counselling and for genetic education. Soc Sci Med 2000;51:831-41.

38 Goizet C, Lesca G, Durr A. Presymptomatic testing in Huntington's disease and autosomal dominant cerebellar ataxias. Neurology 2002;59:1330-6.

39 Hayden MR. Predictive testing for Huntington's disease: a universal model? Lancet Neurol 2003;2:141-2.

Accepted: 10 February 2009 